\title{
Endovascular Treatment of Proximal Aortic Arch Lesions through a Retrograde Approach
}

\author{
Edgar A. Samaniego ${ }^{a}$ Barry T. Katzen ${ }^{b}$ Andreas S. Kreusch ${ }^{c}$ \\ Heiko Uthoff ${ }^{d}$ \\ a Departamento de Cirugía Neuroendovascular, Hospital Eugenio Espejo, Quito, Ecuador; \\ ${ }^{b}$ Division of Vascular and Interventional Radiology, Baptist Cardiac and Vascular Institute, \\ Miami, Fla., USA; ' Department of Radiology, Cantonal Hospital Winterthur, Winterthur, and \\ ${ }^{\mathrm{d}}$ Department of Angiology, University Hospital Basel, Basel, Switzerland
}

\section{Key Words}

Aortic arch · Endovascular treatment · Stenosis · Innominate artery · Carotid artery

\begin{abstract}
Tandem atherosclerotic lesions of the carotid bifurcation and the ipsilateral proximal common carotid artery (CCA) or innominate arteries (IA) can be challenging to treat. A surgical approach may treat the lesion at the carotid bifurcation, but proximal CCA or IA lesions require a major surgical exposure. An endovascular approach is challenging as well since anatomic variations, such as a type III aortic arch, can render navigation very difficult. We report our experience in the hybrid surgical and endovascular treatment of complex proximal CCA and IA lesions. Eleven patients who underwent hybrid procedures with surgical exposure (with or without endarterectomy) of the carotid artery and retrograde endovascular intervention of a proximal lesion were included in the study. The mean percentage of stenosis was $81 \%$. Seven patients underwent a carotid endarterectomy (CEA), and 4 patients underwent only a surgical cutdown for retrograde endovascular access of the IA or left CCA. All procedures were technically successful. Eight patients had no symptoms within 30 days of the procedure. The hybrid retrograde endovascular approach through carotid exposure with or without CEA appears to be effective and safe in selected patients who have a high-risk complex anatomy of tandem lesions.




\section{Introduction}

Tandem atherosclerotic lesions of the carotid bifurcation and the ipsilateral proximal common carotid artery (CCA) or innominate arteries (IA) are uncommon. Akers et al. [1] described a $4.8 \%$ prevalence of these lesions in patients who underwent an aortic arch angiogram for suspected carotid artery disease. However, approximately $80 \%$ of these lesions are symptomatic [2]. Surgical and endovascular treatment of these tandem lesions is challenging. A surgical approach may treat the lesion at the carotid bifurcation, but proximal CCA or IA lesions require a major surgical exposure. An endovascular approach is challenging as well since anatomic variations, such as a type III aortic arch, can render navigation very difficult. Moreover, there is a high risk of rupturing a proximal plaque while accessing distal lesions.

In 1996, Diethrich et al. [3] described a hybrid approach with surgical exposure of the carotid bifurcation, retrograde stenting of proximal CCA or IA lesions, followed by carotid endarterectomy (CEA). This approach offers the advantage of not crossing the ostial aortic arch lesions without distal neuroprotection, especially for patients with difficult arch anatomy and tortuosity. Experience with this hybrid treatment approach is very limited. The purpose of the present study is to report our experience in the treatment of these complex lesions.

\section{Materials and Methods}

Institutional review board approval for this study was obtained, and the need for patient consent for inclusion in the study was waived. A written consent was obtained for the publication of the patients' angiograms. In accordance with the Health Insurance Portability and Accountability Act guidelines, a retrospective review of the electronic medical record system was performed. All adult patients who underwent hybrid procedures with surgical exposure of the carotid artery and an endovascular intervention of a proximal lesion at a single tertiary care medical center between January 1997 and August 2012 were included. CEA was sometimes performed following the endovascular intervention. Demographic characteristics, technical approaches and outcomes were obtained.

\section{Technique}

The decision to treat was based on the preoperative clinical and imaging data and made by a multidisciplinary board formed by endovascular surgeons, vascular surgeons and the referring clinician. If possible, all patients underwent a catheter-based angiogram to allow us to better characterize the proximal and distal lesions and plan the procedure (fig. 1).

Hybrid procedures were performed under general endotracheal anesthesia, cervical block or conscious sedation. All the procedures were performed in a hybrid angiography suite with operating room capabilities. The cervical CCA was exposed and accessed as described previously [4]. A single-wall needle was advanced into the CCA. Upon blood return, a torque wire was advanced under direct fluoroscopic visualization through the proximal stenosis. Over the torque wire, a 6-Fr long sheath was advanced into the CCA and a straight or pigtail (5-Fr) catheter with marker was placed in the arch. This allowed both angiographic evaluation and hemodynamic assessment with simultaneous pressure measurements. The marker catheter was used to obtain a calibrated measure of vessel diameter to assist in stent selection. The wire was then re-introduced, the dilator replaced and the sheath advanced through the proximal stenosis and into the aortic arch. Angiography could be performed via the sheath to confirm the location and extent of stenosis. Based on the angiographic measurements, a stent was then positioned across the area of stenosis. In some cases, road mapping was helpful, but most often the dense calcification was visible under fluoroscopy and used as a landmark. In most patients, the CCA was clamped at the time of stent deployment to decrease the risk of embolic complications (fig. 1).

Before removal of the internal carotid artery (ICA) clamp or vessel loop, the sheath was removed with simultaneous suction being applied through the side port, and back bleeding flowed out through the puncture site to facilitate evacuation of any potential debris. The puncture site was then closed with Prolene suture, 
Fig. 1. A 73-year-old woman presented with episodes of left-hand numbness and weakness. A catheter-diagnostic angiogram demonstrated a high-grade stenosis of the IA (a, arrow), a right subclavian artery occlusion and a highgrade stenosis of the right ICA (b) arrowhead). A balloon-expandable stent was deployed (c). The same sheath could then be advanced through the stent to obtain a post-stenting angiogram (d).
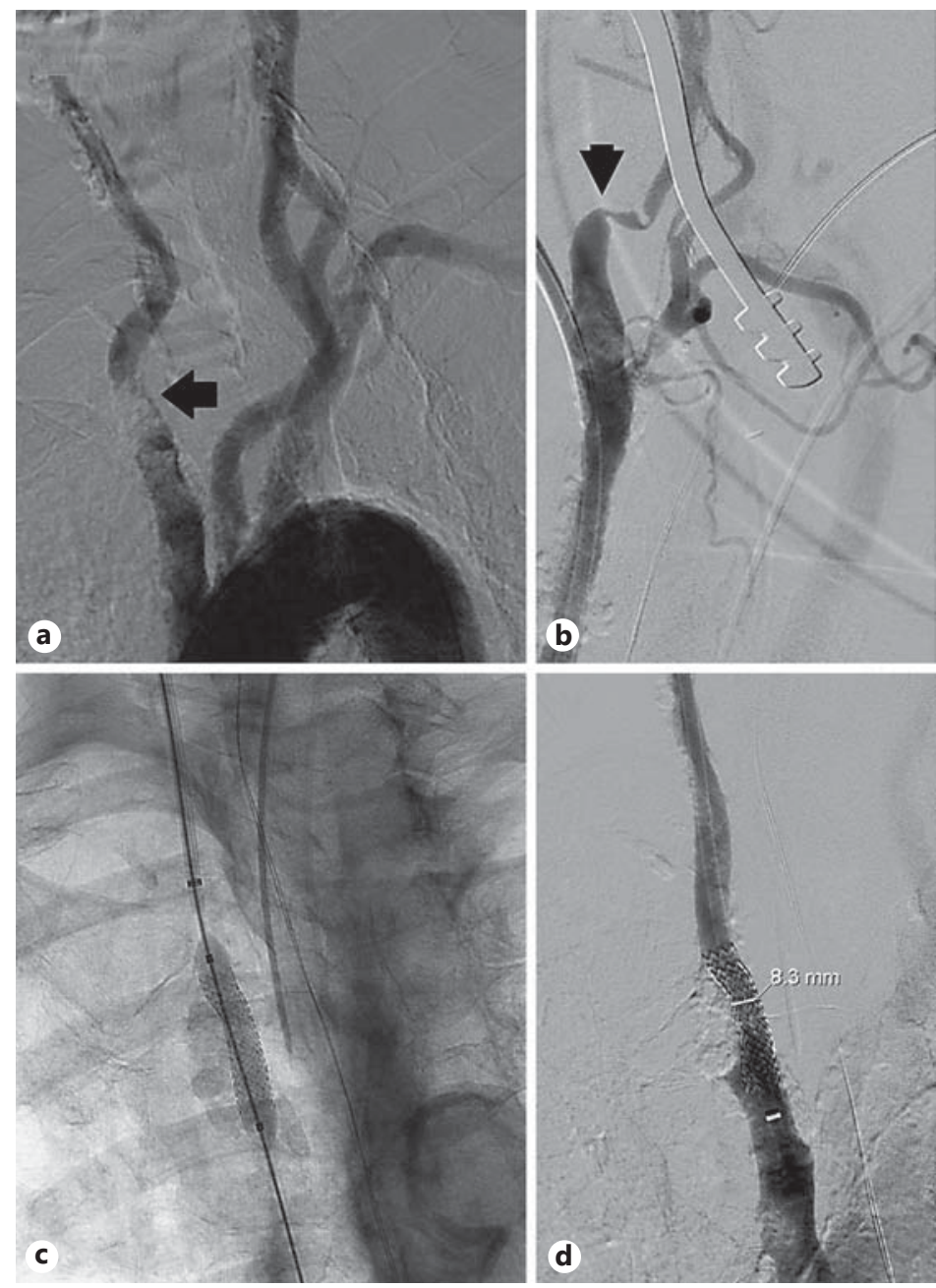

generally a purse string. Flow was then restored first in the external carotid artery and then the ICA to minimize intracranial embolization.

If a synchronous CEA was to be performed, an arteriotomy incorporated the puncture site and was extended across the ICA stenosis. Any debris from the proximal angioplasty was then thoroughly vented before a shunt was inserted. A standard endarterectomy was then performed with routine tacking sutures and patch closure. At completion of the endovascular procedure, any type of anticoagulation was stopped. All patients were in a dual antiplatelet regimen before and for at least 3 months after the procedure.

\section{Results}

Fourteen patients who underwent hybrid interventions were identified. Three patients were not included in the analysis due to incomplete demographic and radiographic information. There were 5 men and 6 women with a mean age of $70 \pm 13$ years (table 1 ). Hypertension was present in the whole cohort. All patients were symptomatic at the time of intervention, and most symptoms were related to brain ischemia.

All patients had type II and III aortic arches (fig. 2), except for 1 patient with a type I arch who underwent the hybrid procedure due to diffuse atherosclerosis of aortoiliac vasculature and supra-aortic vessels. The mean percentage of stenosis was 81\% (table 2). Eight proce- 


\begin{tabular}{l|l}
\hline Intervent Neurol 2014;3:41-47 \\
\hline DOI: 10.1159/000369302 & $\begin{array}{l}\text { ( ) 2014 S. Karger AG, Basel } \\
\text { www.karger.com/ine }\end{array}$ \\
\hline
\end{tabular}

Samaniego et al.: Endovascular Treatment of Proximal Aortic Arch Lesions through a Retrograde Approach

Table 1. Demographic characteristics

\begin{tabular}{|c|c|c|c|c|c|c|}
\hline No. & Age & HTN & $\mathrm{DM}$ & HCD & Smoking & Symptoms \\
\hline 1 & $60 \mathrm{~s}$ & 1 & 0 & 0 & 1 & Arm weakness \\
\hline 2 & $70 \mathrm{~s}$ & 1 & 0 & 1 & 1 & $\begin{array}{l}\text { Subclavian steal, amaurosis fugax and arm } \\
\text { claudication }\end{array}$ \\
\hline 3 & $60 s$ & 1 & 0 & 1 & 0 & Syncopal episodes \\
\hline 4 & 80 s & 1 & 1 & 1 & 1 & Hand numbness \\
\hline 5 & $80 s$ & 1 & 0 & 0 & 1 & Arm weakness and claudication \\
\hline 6 & $70 \mathrm{~s}$ & 1 & 0 & 1 & 1 & Hand weakness and numbness \\
\hline 7 & $60 s$ & 1 & 1 & 1 & 1 & Dizziness and amaurosis fugax \\
\hline 8 & $50 \mathrm{~s}$ & 1 & 0 & 0 & 0 & Subclavian steal syndrome \\
\hline 9 & $60 \mathrm{~s}$ & 1 & 0 & 0 & 1 & Arm weakness and episodic aphasia \\
\hline 10 & $70 s$ & 1 & 1 & 0 & 1 & Arm weakness \\
\hline 11 & $50 \mathrm{~s}$ & 1 & 1 & 1 & 1 & Amaurosis fugax \\
\hline
\end{tabular}

HTN = Hypertension; DM = diabetes; $\mathrm{HCD}$ = hypercholesterolemia.
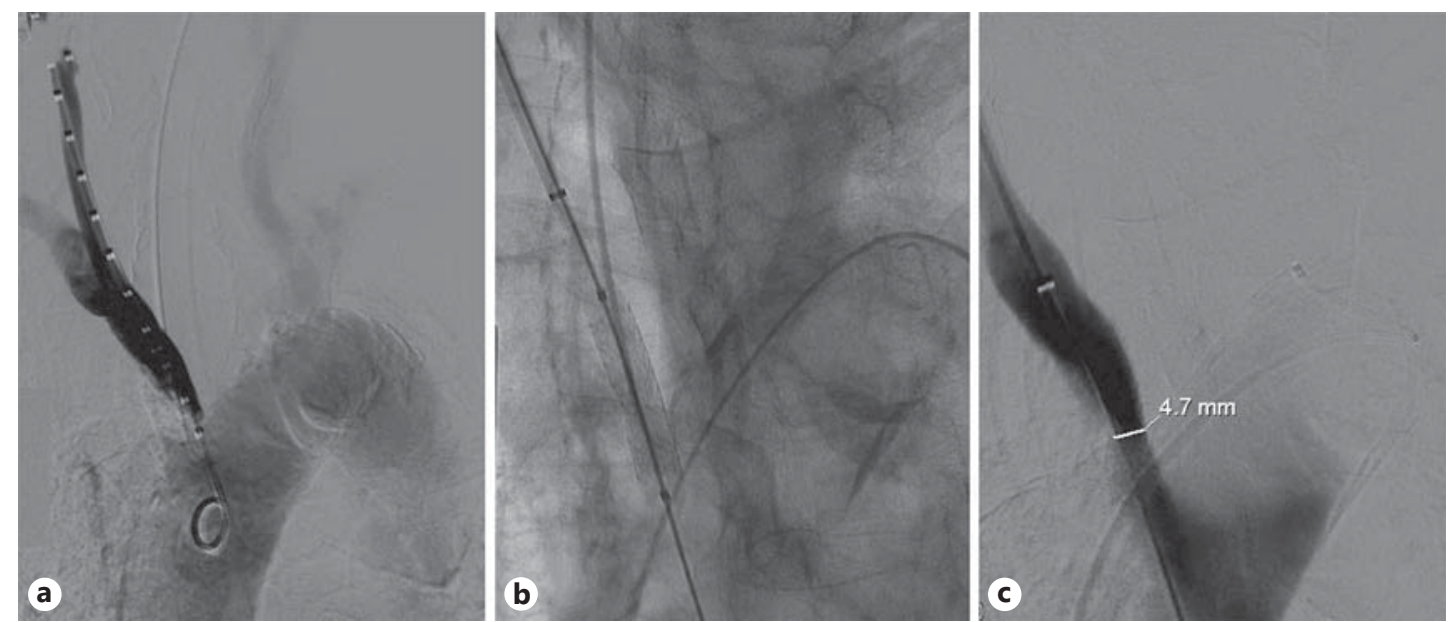

Fig. 2. An 80-year-old woman with left-hand weakness was referred for angiography and endovascular treatment of an IA stenosis. A retrograde aortogram obtained with a pigtail catheter demonstrated a type III aortic arch (a) and a high-grade stenosis at the origin of the IA. Post-stenting angiography demonstrated significant improvement of the stenosis $(\mathbf{b}, \mathbf{c})$.

dures were performed with general anesthesia and 3 with moderate sedation and cervical blocking. Seven patients underwent a concurrent CEA and 4 a surgical cutdown for retrograde endovascular access of the IA or left CCA only.

All procedures were technically successful. Only 1 patient had an asymptomatic focal carotid dissection. In 7 patients, the length of hospitalization following the procedure was at most $72 \mathrm{~h}$. Eight patients had no symptoms within 30 days of the procedure, 1 patient had mild hoarseness (surgical cutdown) and another patient neck swelling (CEA); both resolved without treatment. These 2 complications were probably related to the surgical manipulation of the neck. One patient was hospitalized for 75 days due to other comorbidities, and it was unclear if he remained asymptomatic after the procedure. There were no neurological adverse events. 
Table 2. Technical characteristics

\begin{tabular}{|c|c|c|c|c|c|c|c|c|c|}
\hline No. & Arch & $\begin{array}{l}\text { Proximal } \\
\text { lesion } \\
\text { location }\end{array}$ & $\begin{array}{l}\text { Steno- } \\
\text { sis, \% }\end{array}$ & $\begin{array}{l}\text { Reason for retrograde } \\
\text { approach }\end{array}$ & Procedure & $\begin{array}{l}\text { Post- } \\
\text { stenting } \\
\text { stenosis, \% }\end{array}$ & $\begin{array}{l}\text { Compli- } \\
\text { cations }\end{array}$ & $\begin{array}{l}\text { Hospi- } \\
\text { talization, } \\
\text { days }\end{array}$ & 30-day outcome \\
\hline 1 & $\begin{array}{l}\text { III } \\
\text { bovine }\end{array}$ & L CCA & 80 & Arch anatomy & $\begin{array}{l}\text { Surgical cutdown, } \\
\text { L CCA stenting }\end{array}$ & 0 & $\begin{array}{l}\text { Focal } \\
\text { dissection }\end{array}$ & 2 & Asymptomatic \\
\hline 2 & II & IA & 95 & Atherosclerotic burden & $\begin{array}{l}\text { Surgical cutdown, } \\
\text { IA stenting }\end{array}$ & 0 & None & 3 & Asymptomatic \\
\hline 3 & I & IA & 60 & Atherosclerotic burden & $\begin{array}{l}\text { R CEA, } \\
\text { IA stenting }\end{array}$ & & None & 2 & Asymptomatic \\
\hline 4 & $\begin{array}{l}\text { II } \\
\text { bovine }\end{array}$ & IA & 90 & Atherosclerotic burden & $\begin{array}{l}\text { R CEA, } \\
\text { IA stenting }\end{array}$ & 0 & None & 2 & Asymptomatic \\
\hline 5 & III & IA & 85 & Arch anatomy & $\begin{array}{l}\text { Surgical cutdown, } \\
\text { IA stenting }\end{array}$ & 50 & None & 2 & Asymptomatic \\
\hline 6 & III & IA & 85 & Arch anatomy & $\begin{array}{l}\text { R CEA, } \\
\text { IA stenting }\end{array}$ & 15 & None & 4 & Neck swelling \\
\hline 7 & & L CCA & 70 & $\begin{array}{l}\text { Diffuse aortoiliac } \\
\text { disease }\end{array}$ & $\begin{array}{l}\text { Surgical cutdown, } \\
\text { L CCA stenting }\end{array}$ & & None & 14 & Hoarseness \\
\hline 8 & III & L CCA & 85 & $\begin{array}{l}\text { Diffuse aortoiliac } \\
\text { disease }\end{array}$ & $\begin{array}{l}\text { L CEA, } \\
\text { L CCA stenting }\end{array}$ & 10 & None & 2 & Asymptomatic \\
\hline 9 & II & L CCA & 65 & Arch anatomy & $\begin{array}{l}\text { L CEA, } \\
\text { L CCA stenting }\end{array}$ & 0 & None & 12 & Asymptomatic \\
\hline 10 & II & L CCA & 90 & Atherosclerotic burden & $\begin{array}{l}\text { L CEA, } \\
\text { L CCA stenting }\end{array}$ & 10 & None & 2 & Asymptomatic \\
\hline 11 & $\begin{array}{l}\text { III } \\
\text { bovine }\end{array}$ & L CCA & 90 & Arch anatomy & $\begin{array}{l}\text { L CEA, } \\
\text { L CCA stenting }\end{array}$ & 0 & None & 75 & NA \\
\hline
\end{tabular}

\section{Discussion}

Recent randomized trials have shown equivalent results for carotid stenting compared to CEA when a composite end point of death, stroke, and myocardial infarction was analyzed, both in the setting of asymptomatic and symptomatic carotid disease. In these trials, patients with more extensive disease affecting the proximal CCA or IA were excluded $[5,6]$. The treatment of patients with extensive occlusive disease of the carotid bifurcation and proximal supra-aortic vessels can be challenging. In 1999, a meta-analysis comparing the open surgical outcome in subclavian and brachiocephalic artery obstruction with stenting using the Palmaz stent demonstrated that in contrast to surgery, complications with stenting were minor [7]. Since then, few case series have demonstrated the feasibility and superiority of catheterbased endovascular techniques in the treatment of supra-aortic vessel stenosis.

The advantages of a hybrid approach are numerous. The procedure can be accomplished using the same cervical incision, therefore avoiding the need for mediastinotomy and major open surgical interventions. Temporary occlusion of the CCA during angioplasty and stenting can provide excellent protection from distal cerebral embolization [8, 9]. Moreover, the tortuosity of supra-aortic vessels, the potential for friable atherosclerotic debris, and the current designs of neuroprotection devices preclude the use of distal protection through a transfemoral approach [10]. 
Retrograde navigation into the CCA or IA avoids accessing aortoiliac vessels in patients with a large atherosclerotic burden and can be performed with considerably shorter procedure time. In selected patients, the procedure can be performed with moderate sedation and cervical block, avoiding complications from general anesthesia and improving the monitoring for possible neurological complications in patients who are awake, but this depends on patient anatomy and surgeon preference.

This report confirms previous findings suggesting that retrograde angioplasty and stenting of proximal lesions with surgical exposure of the carotid artery is technically feasible and safe. In a meta-analysis published by Sfyroeras et al. [2], the 30-day periprocedural mortality and stroke rate were 0.7 and $1.5 \%$, respectively.

High-grade tandem stenoses affecting the ICA and the CCA or IA can become symptomatic due to embolic or hemodynamic events [11]. Moreover, it can be difficult to determine which lesion is truly symptomatic. Therefore, the aim should be to treat both proximal and distal lesions. A hybrid approach allows simultaneous repair. Hemodynamic and clinical principles suggest that a proximal lesion is treated first, which can compromise inflow into a diseased second tandem lesion [11].

We recommend primary stenting instead of angioplasty alone in the treatment of proximal supra-aortic lesions. In the meta-analysis performed by Sfyroeras et al. [2], only 2 of 133 patients in whom a stroke occurred during the procedure underwent angioplasty [2,12]. All the stents used in our series are balloon-expandable stents. These allow precise deployment and have an excellent radial force [13]. The use of direct stenting requires precise vessel sizing and cautious slow inflation given the densely calcified nature of these ostial lesions. Moreover, almost half of the target vessels in our series were IA, which can be difficult to treat. IA usually have a large diameter and short length, narrowing stent selection. Additionally, the IA take-off angle from aortic arches type II and III can further challenge an anterograde approach. In this setting, a hybrid retrograde technique is extremely useful. The stents included Palmaz stents (Cordis Corporation, Miami Lakes, Fla., USA), Express biliary stents (Boston Scientific, Natick, Mass., USA) and iCAST covered stents (Atrium, Hudson, N.H., USA). The stent should be placed 1-2 mm into the aorta to assure lesion coverage [10].

\section{Technical Aspects}

In general, the retrograde hybrid cervical approach is selectively used. It is advised in extremely tortuous arch anatomy; aortoiliac-femoral occlusive disease precluding femoral access; near-occlusive lesions with no clear funnel at the take-off from the aorta; treatment of tandem CCA and bifurcation stenosis at the time of CEA, and failed femoral approach [14].

A 0.35 -inch soft-tipped, steerable guide wire is preferred to cross the proximal lesion. The entire retrograde angioplasty and stenting procedure is preferably done with occlusion of the distal CCA by a clamp or vessel loop. Since most common carotid ostial stenting is done without embolic protection, it is important to aspirate the blood within the carotid artery through the sheath valve, thereby flushing the carotid artery prior to restoration of flow into the ICA $[10,11,13]$.

\section{Conclusion}

The retrograde approach through carotid exposure with or without CEA appears to be an effective and safe treatment in selected patients who have high-risk complex anatomy or tandem lesions. 
Samaniego et al.: Endovascular Treatment of Proximal Aortic Arch Lesions through a Retrograde Approach

\section{Disclosure Statement}

H.U. was supported by a research grant of the University of Basel, Switzerland.

\section{References}

1 Akers DL, Markowitz IA, Kerstein MD: The value of aortic arch study in the evaluation of cerebrovascular insufficiency. Am J Surg 1987;154:230-232.

-2 Sfyroeras GS, et al: A meta-analysis of combined endarterectomy and proximal balloon angioplasty for tandem disease of the arch vessels and carotid bifurcation. J Vasc Surg 2011;54:534-540.

-3 Diethrich EB, et al: Percutaneous techniques for endoluminal carotid interventions. J Endovasc Surg 1996;3: 182-202.

-4 Samaniego EA, et al: Intracranial angioplasty and stenting through direct carotid puncture. J Neuroimaging 2013;23:207-210.

-5 Sheffet AJ, et al: Design of the Carotid Revascularization Endarterectomy versus Stenting Trial (CREST). Int J Stroke 2010;5:40-46.

6 Featherstone RL, Brown MM, Coward LJ: International carotid stenting study: protocol for a randomised clinical trial comparing carotid stenting with endarterectomy in symptomatic carotid artery stenosis. Cerebrovasc Dis 2004;18:69-74.

-7 Hadjipetrou P, et al: Percutaneous revascularization of atherosclerotic obstruction of aortic arch vessels. J Am Coll Cardiol 1999;33:1238-1245.

-8 Tsutsumi M, et al: Cerebral protection during retrograde carotid artery stenting for proximal carotid artery stenosis: technical note. Neurol Med Chir (Tokyo) 2007;47:285-287, discussion 287-288.

-9 Payne DA, et al: Cerebral protection during open retrograde angioplasty/stenting of common carotid and innominate artery stenoses. Br J Surg 2006;93:187-190.

10 Allie DE, et al: Intraoperative innominate and common carotid intervention combined with carotid endarterectomy: a 'true' endovascular surgical approach. J Endovasc Ther 2004;11:258-262.

11 Grego F, et al: Synchronous carotid endarterectomy and retrograde endovascular treatment of brachiocephalic or common carotid artery stenosis. Eur J Vasc Endovasc Surg 2003;26:392-395.

$\$ 12$ Sullivan TM, et al: Angioplasty and primary stenting of the subclavian, innominate, and common carotid arteries in 83 patients. J Vasc Surg 1998;28:1059-1065.

13 Garg N, et al: Retrograde supra-aortic stent placement combined with open carotid or subclavian artery revascularization. Vasc Endovascular Surg 2011;45:527-535.

14 Criado FJ: Endovascular techniques for supra-aortic trunk intervention. Perspect Vasc Surg Endovasc Ther 2007;19:231-237. 